\title{
Pluridiscursividad de la noción de vida cotidiana en las ciencias sociales
}

\author{
Multiple discourses of the notion of everyday life in social sciences \\ Pluridiscursividad da noção da vida cotidiana nas ciências sociais
}

\author{
Katy Luz Millán Otero ${ }^{1}$ \\ Recibido: 10.01.2017 - Arbitrado: 28.02.2017 - Aprobado: 03.03.2017
}

\begin{abstract}
Resumen
Las ciencias sociales se han ocupado por décadas de los actos cotidianos, de la vida del hombre común, de sus prácticas e interacciones sociales, así bien, la vida cotidiana puede resultar en sí misma una noción obvia y automática, encierra elementos complejos para entender la historicidad del mundo y las relaciones sociales de los individuos que la integran. El objetivo de esta investigación es hacer una revisión teórica del concepto de vida cotidiana entre 1990 y 2014, desde tres tradiciones de las ciencias sociales: filosofía, antropología y sociología. Se utilizó cómo método un diseño cualitativo, enmarcado en un estudio teórico clásico. La revisión teórica se hizo en revistas de acceso abierto. Los resultados centrales del estudio expresan una pluralidad en el concepto de acuerdo a la disciplina y autores que lo aborden, de igual manera, se hallaron características homogéneas como la intersubjetividad, el carácter histórico, espacial y temporal que la compone. Conclusiones: es esencial el análisis crítico y reflexivo de la vida cotidiana en tanto es la vía para responder los interrogantes que encierran las sociedades.
\end{abstract}

Palabras claves: Vida cotidiana, cotidianidad, antropología, sociología, filosofía.

\begin{abstract}
Social sciences have dealt with everyday acts for decades, the ones of the life of ordinary men, their social practices and interactions, which is why, if common life may be itself an obvious and automatic notion, it involves complex elements to understand the history of the world and the social relationships of its forming members. The objective of this research is to perform a theoretical revision of the concept of everyday life between the years 1990 and 2014 from three of the traditional social sciences: philosophy, anthropology and sociology. It is a qualitative design method, framed within a classical theoretical study. This revision was done through open access magazines. The main results of the study express a plurality of concepts according to the discipline and authors that describe it, as well as some homogeneous characteristics such as intersubjectivity and the historical, spatial and temporal character that composes it. Discussion: the critical and reflective analysis of everyday life is essential given that is the way to answer the questions that societies embrace.
\end{abstract}

Key words: Everyday life, familiarity, anthropology, sociology, philosophy.

\footnotetext{
${ }^{1}$ Psicóloga, Magíster en Estudios Socioespaciales de la Universidad de Antioquia. Docente Investigadora de la Fundación Universitaria Luis Amigó. Medellín, Colombia, katy.millanot@amigo.edu.co

Citación del artículo: Millán, K. (2017). Pluridiscursividad de la noción de vida cotidiana en las ciencias sociales. Revista Katharsis, N 23, enero-julio 2017, pp.202-217, Disponible en http://revistas.iue.edu.co/index.php/katharsis
} 


\section{Resumo}

As ciências sociais têm ocuparam-se por décadas dos actos da vida quotidiana do homem comum, suas práticas e interacções sociais, bem, a vida quotidiana pode ser em si mesmo um conceito óbvio e automático, contém elementos complexos para entender o historicidade do mundo e as relações sociais dos membros individuais. $\mathrm{O}$ objetivo deste investigação é fazer uma revisão teórica do conceito da vida quotidiana entre 1990 e 2014, a partir de três tradições de ciências sociais: filosofia, antropologia e sociologia. Utilizou-se como método um desenho qualitativo, enquadrado num estudo teórico clássico. A revisão teórica fez-se em jornais de acesso aberto. Os resultados centrais do estudo expressam uma pluralidade no conceito de acordo à disciplina e autores que o abordem, do mesmo modo, se acharam características homogêneas como intersubjetividade, o caráter histórico, espacial e caráter temporal que a compõe. Conclusões: è esencial à análise crítica e reflexivo da vida quotidiana em tanto è a via pra responder os interrogantes que encerram as sociedades.

Palavras-chave: vida quotidiana, cotidianidad, antropologia, sociologia, filosofia.

\section{Introducción}

Pensar la vida cotidiana no sólo consiste en dirigir la mirada hacia los actos diarios habituales de las personas, tales como el comer, dormir, laborar, estudiar, etc. Ello implica ampliar los horizontes del pensamiento, para contemplarla como el espacio donde los seres humanos construyen y despliegan su subjetividad, su identidad social, vale decir, el centro de la historia personal (Castoriadis, 1993).

La vida cotidiana es el escenario complejo y plural, en donde mujeres y hombres configuran los sentimientos, pensamientos, capacidades propias del lugar asumido en el espacio sociovital, que difiere de otros contextos en estructura y contenido (Castro, 1996). Como obviedad, la vida cotidiana está limitada a la vivencia de cada sujeto, a sus circunstancias, no obstante, las Ciencias Sociales han percibido y destacado en ella, una categoría de análisis sin la cual no pueden ser pensadas otras nociones como la subjetividad y la identidad social (Arellano, Chávez \& Anguiano, 2012). Los hombres participan en las distintas esferas de la vida cotidiana con todos los elementos de su existencia, trascendiendo el espacio íntimo, la heterogeneidad que caracteriza la estructura de la vida cotidiana, permite comprenderla como espacio de atravesamiento y de relaciones que mutuamente se influyen y modifican (Castro, 2004).

Ahora bien, ¿qué importancia tiene el revisar en las teorizaciones de las Ciencias Sociales la noción de vida cotidiana? Al respecto, Heller (1991) considera que la vida cotidiana es el espejo de la historia, el cual refleja los fenómenos sociales, las estrategias y los espacios de interacción social en que se reproducen. Entenderla es involucrarse en los por qué de los individuos y de sus interacciones sociales, en tanto, la vida cotidiana se focaliza en las practicas humanas, éstas tienen temporalidad y susceptibles de ser historiadas (Collado, 2002). Así para conocer una sociedad, se parte de estudiar a sus individuos y los grupos a los que pertenecen; sus vivencias, prácticas sociales y discursivas, y una de las formas de lograrlo es a través del estudio de la vida cotidiana (Perera, 1997).

Citación del artículo: Millán, K. (2017). Pluridiscursividad de la noción de vida cotidiana en las ciencias sociales. Revista Katharsis, N 23, enero-julio 2017, pp.202-217, Disponible en http://revistas.iue.edu.co/index.php/katharsis 
Y, ¿para qué descubrir lo que ya es evidente? Como responde Begout (2009), para tener una evidencia vivida en tanto el "carácter problemático de lo cotidiano es su ser enigmático, oculto; porque en la cotidianidad se vive la paradoja de que lo más familiar y lo más próximo es en realidad lo más lejano y lo más extraño" (p.18-19).

La vida cotidiana se ofrece como "lugar privilegiado para el análisis de las relaciones entre procesos macro y microsociales. Así, constituye una especie de «espacio bisagra» de las ciencias sociales y humanísticas, por consiguiente, reclama continuar su desarrollo acercándose a las precisiones de un enfoque transdisciplinario" (Perera, 2012). Atendiendo a esto, el objetivo del presente artículo es revisar la producción teórica acerca de la vida cotidiana, entre 1990 y 2014, desde tres tradiciones de las ciencias sociales: filosofía, antropología y sociología, visibilizando los distintos autores y categorías asociadas al concepto.

\section{Método}

\section{Diseño}

Esta investigación se basó en un estudio teórico clásico, el cual presenta avances teóricos, estudios y revisión sin utilizar estadísticas para llevar a cabo la conceptualización de la tesis (Montero \& León, 2007).

\section{Procedimiento}

La búsqueda de artículos de revisión, se realizó a través de bases de datos especializadas como Redalyc, SciELO, Digitalia, Ebsco, Science-Direct, Latindex, Digitalia, Google Académico. La búsqueda se centró en palabras claves y el título; los términos usados fueron las tradiciones: sociología, antropología y filosofía, combinadas con vida cotidiana.

La búsqueda bibliográfica fue realizada entre los meses de febrero a septiembre de 2015; se incluyó artículos de revisión y algunos libros. Los criterios de búsqueda fueron: artículos o libros de revisión teórica publicados en revista científicas entre 1990 y 2014; se seleccionó textos que relacionaran vida cotidiana con las tradiciones de las ciencias sociales priorizadas: filosofía, sociología, antropología. En total se recopiló setenta fuentes que luego de ser revisadas se redujo a cincuenta

La estrategia del análisis de contenido del estudio teórico clásico, permitió la emergencia de categorías analíticas desarrolladas en los apartados de resultados en relación a las tres tradiciones de las ciencias sociales revisadas: filosofía, sociología, antropología, para este fin se utilizó el programa de software Atlas Ti 7 para apoyar el análisis. Las categorías emergentes se abordan en el apartado de resultados.

\section{Resultados}

\section{La reflexión filosófica de la vida cotidiana}

La vida cotidiana ha sido un tema de interés histórico para la filosofía, aunque desde sus principios no tuvo el protagonismo actual. Desde Platón se empieza a leer a través de sus

Citación del artículo: Millán, K. (2017). Pluridiscursividad de la noción de vida cotidiana en las ciencias sociales. Revista Katharsis, N 23, enero-julio 2017, pp.202-217, Disponible en http://revistas.iue.edu.co/index.php/katharsis 
diálogos el interés en la vida ordinaria, no como eje central de su obra, sino tiendo como propósito la contemplación de las ideas. Aristóteles por su parte, referencia la vida cotidiana desde los ejemplos que usa para ilustrar su doctrina. En la teología moderna y contemporánea, influenciados por la reforma protestante y del cristianismo se puede también, hallar visos en torno a la vida ordinaria (Cuéllar, 2009).

Para Cuéllar (2009), el estudio de la vida cotidiana desde la filosofía brinda el "suficiente peso ontológico para ser estudiada como un marco de referencia legítimo para el crecimiento personal y social de cualquier ser humano, ya que por él discurre - de una o de otra manera - la vida de casi todos los hombres" (p.13). Empero, no todos los filósofos compartieron esta noción, "para Hegel la vida cotidiana quedaba por principio fuera de todo pensamiento filosófico" (Díaz, 2010, p.41). Fue Martin Heidegger el primer filósofo en reconocer la importancia de la vida cotidiana en la reflexión sobre la realidad social, seguido de la fenomenología que acogió el concepto para analizar la forma en que el ser humano conoce y se desenvuelve en la cotidianidad (Zamora, 2005).

Algunos pensadores que se han ocupado de teorizar acerca de la vida cotidiana han sido Descartes, Francis Bacon, Kant, Augusto Comte, Marx, Bentham y John Stuart Mill, si bien no conceptualizaron formalmente el significado de la vida cotidiana, sus aportes, desde las ciencias físico-matemáticas, la incipiente sociología y la dimensión práctica e histórica de la existencia humana, abonaron el terreno para hablar de los fenómenos vinculados a la vida cotidiana desde la perspectiva social. Pensadores del siglo XX como Sören Kierkegaard, Edmund Husserl, Martín Heidegger, Hannah Arendt, Alasdair MacIntyre, Charles Taylor, Leonardo Polo, Alejandro Llano, Pier Paolo Donati, Xabier Etxeberría, R. Alvira, entre otros; han puesto la mirada, a través de sus escritos, a este tema central para la vida de cualquier persona (Cuéllar, 2009).

Alfred Schütz se constituye en uno de los filósofos que ha volcado su pensamiento al estudio de esta noción, son claves en la obra del austriaco los conceptos del mundo social y vida cotidiana (Estrada, 2000). Para Schutz el lugar de reflexión de la vida cotidiana es donde se construyen los significados, donde se actúa de forma inconsciente. El autor distingue entre el significado que se le asigna a las acciones cotidianas, consideradas automáticas y el grado con que se capta dicho significado (Hernández \& Galindo, 2007).

Estrada (2000), retomando a Schütz, plantea que el mundo de la vida es el espacio de las acciones del sujeto, así como el recipiente de las intervenciones en dicho mundo. "El problema de la vida cotidiana se expresa en las relaciones de los actores sociales entre sí, en cómo comprenden y constituyen la realidad social" (p.112). El análisis de las estructuras del mundo de la vida de Schütz, "puede interpretarse como una sociología general de la vida cotidiana” (Grathoff, 1989, p.107). Así pues, amplía la reflexión sobre la construcción de otro mundo social, un mundo intersubjetivo en una estructura previa y fundante de nuestra experiencia de la vida.

La Vida cotidiana está sostenida por continuidades intersubjetivas que ligan al sujeto a la realidad del sentido común en la que actúa, "está de antemano dada, esto es, es un mundo de construcciones sociales (lenguaje, saber, estructura social) preconstituido y socializado que ofrece permanentemente los estilos étnicos y sociales de las experiencias vivenciales de la vida cotidiana" (Grathoff, 1989, p.115-116).

Para Schütz finalmente el mundo de la vida constituye la realidad eminente, el mundo al alcance del ser humano donde desarrolla sus proyectos y planes de vida. Es un mundo Citación del artículo: Millán, K. (2017). Pluridiscursividad de la noción de vida cotidiana en las ciencias sociales. Revista Katharsis, N 23, enero-julio 2017, pp.202-217, Disponible en http://revistas.iue.edu.co/index.php/katharsis 
ofrecido a su experiencia e interpretación, donde convergen sus acciones e interacciones que experimenta como un mundo intersubjetivo (Acevedo, 2011).

Sierra (2013) destaca cómo varios filósofos han tratado de pensar la vida cotidiana más allá de la cotidianidad, convirtiéndola en su objeto de reflexión. Algunos de estos pensadores son: la filosofía del Porvenir de Feuerbach; los primeros escritos de Marx; la microscopia de Simmel; el análisis histórico-crítico de la modernidad de Benjamín; el pensamiento fenomenológico desde Husserl a M. Ponty; la analítica existencial de Heidegger, la cotidianidad crítica de Lefebvre y Heller, o la invención de lo cotidiano en DeCerteau.

A pesar de la importancia de la vida cotidiana, es difícil escapar a la simpleza del concepto; Cuellar (2009) la refiere como "el tipo de vida que vive cualquier hombre o mujer sin ningún tipo de circunstancia especial que vuelva extraordinaria su vida (...), perfilado por ciertas tradiciones y cultura, creencias e idiosincrasia" (p.25), que facilitan la vinculación y el reconocimiento con las otras personas y la construcción de su entorno, en un tiempo y lugar explícitos. Para Perera (1997), esta categoría ha sido definida como el espacio de construcción de actividades de producción y relaciones sociales que regulan la existencia material y simbólica de las personas en un contexto social, económico e histórico determinado.

Orellana (2009), destaca que la vida cotidiana no sólo es una referencia teórica, que ilustra la realidad de los actores, sino una narración basada en la experiencia donde se obtiene la "comprensión de las estructuras simbólicas de las acciones humanas y la interpretación de su intencionalidad inmersa en los significados y sentidos de las personas, las cuales están representados y registradas en el discurso que se comunica en la Vida Cotidiana" (p.9).

Berger y Luckmann parten del hecho de reconocer que el tipo de conocimiento que orienta a la vida cotidiana de los sujetos es un saber que éstos asumen como ordenado, coherente y objetivo de la realidad en la que se hallan inmersos, generalmente a través del lenguaje que es compartido por todos los sujetos sociales, de tal suerte que dicha vida cotidiana no necesita verificaciones sobre su sola presencia y más allá de ella, está ahí sencillamente como [...] [...factibilidad...] evidente de por sí e imperiosa (Camarena Adame \& Tunal Santiago, 2008, p.97).

Por su parte, Acosta (2013), retomando a Miguel Agustín Romero (2001), argumenta que el saber filosófico en relación a la vida cotidiana tendría que expresarse no sólo en términos "de mayor percepción clara y distinta de la realidad, sino en término de mayor sensibilización, de humanización, de conciencia de nuestra pertenencia a la colectividad humana... Se expresaría, además, en la solidaridad con los demás” (p.12) y en la comprensión de que se comparte una identidad común. Retomando a Bauman, Acosta (2013) afirma que la filosofía en los tiempos posmodernos busca que la persona humana "se reencante con el mundo después del desencanto que le ha producido el desarrollo de la historia y de la propia vida cotidiana" (p.13).

Una de las categorías en relación a la vida cotidiana es la cotidianidad. Sin embargo, para la mayor parte de la tradición filosófica occidental este concepto no ha sido un tema filosófico (Santos Herceg, 2014). Como lo indica Bruce Bégout (2009), "la filosofía con Citación del artículo: Millán, K. (2017). Pluridiscursividad de la noción de vida cotidiana en las ciencias sociales. Revista Katharsis, N 23, enero-julio 2017, pp.202-217, Disponible en http://revistas.iue.edu.co/index.php/katharsis 
extraña unanimidad ha denegado el mundo cotidiano (...), raramente ha hecho un esfuerzo por comprenderlo. La filosofía se ha contentado con verlo bajo el aspecto de la banalidad servil, para así apartarse de él inmediatamente" (p.11). Esto está directamente relacionado con la pérdida del sentido común como categoría analítica importante en el mundo social, como lo señala Hannah Arendt (2013), en su texto "La condición humana" responsabiliza a los filósofos de la pérdida del sentido común y, por ende, el descuido de la vida cotidiana, de la vida juntos.

Sierra (2013) detalla que una filosofía de la cotidianidad es "allí donde se vive la 'inquietud original del existir', con la inseguridad, la incredulidad, la duda, el miedo y la incertidumbre que la acompañan" (p.9). Retomando a Begout (2005), es en la cotidianidad donde se experimenta la problematicidad misma de la existencia humana, así sea en una especie de "escepticismo carnal, allí se vive la experiencia del mundo en su profunda extrañeza y, junto con esta, también la extrañeza en el interior de nosotros mismos que tal extrañeza nos causa" (p.26).

Humberto Giannini desde la filosofía existencial ha teorizado acerca de la cotidianidad. El autor reconoce que la cotidianidad está presente en todos los espacios de la vida social, pero "se cubre de un manto invisible para la conciencia. Develarla requiere de un esfuerzo intelectual y reflexivo" (Zamora, 2005, p.127).

Siguiendo a Giannini, Zamora (2005) detalla tres sentidos acerca de la vida cotidiana claves para su comprensión: la cotidianidad es lo que pasa todos los días, con esta premisa básica y evidente destaca la dicotomía de lo cotidiano, asociado a la rutina y los pensamientos mecánicos, con lo no cotidiano que inscribe la transgresión y los pensamientos genuinos y reflexivos. El otro sentido es la Vida cotidiana como reflexión que implica interrogarse por el sentido (para qué) y la fundamentación (por qué) de la existencia. La vida cotidiana como la vida en su totalidad visible espaciotemporal pone de relieve la historicidad y variabilidad de la cotidianidad, al igual que las características topográficas que la condensa (Morales, 2001).

La cotidianidad reproduce y/o transforma las necesidades del hombre y las relaciones que éste establece con ellas, las metas sociales, formas y vías disponibles para su satisfacción (Perera, 1997). La cotidianidad es importante porque en ella se encuentra la respuesta a la pregunta "por el sentido de nuestras vidas y se puede tener una mayor conciencia de la propia identidad, de la actividad productiva y reproductiva, de la responsabilidad y libertad en la prosperidad propia y la de los demás” (Cuellar, 2009, p.28).

Sumado a la cotidianidad, Cuellar (2009) ha ahondado sobre las categorías de la vida cotidiana, de las cuales destaca:

- El reconocimiento de la dimensión secular: "reconocimiento del lugar originario en donde de manera natural y novedosa — en la vida ordinaria — puede discurrir la vida del ser humano, en este mundo complejo y plural" (p.31).

- Dimensión antropológica: En la vida cotidiana se puede encontrar e ir forjando el sentido de la existencia mediante el "autoconocimiento, la mirada prospectiva y pequeñas o grandes metas concernientes a la vida en familia, el matrimonio, el trabajo o la vida de relación social" (p.32).

- Dimensión ética: Está conectado con la "ontología de la persona con su propia naturaleza inviolable y sagrada, fuente de sus derechos más legítimos y responsabilidades para consigo mismo y con otros" (p.32)

Citación del artículo: Millán, K. (2017). Pluridiscursividad de la noción de vida cotidiana en las ciencias sociales. Revista Katharsis, N 23, enero-julio 2017, pp.202-217, Disponible en http://revistas.iue.edu.co/index.php/katharsis 
- Dimensión relacional: Hace énfasis a la intersubjetividad, entendiendo ésta, a la comunicación entre personas a través de su pensamiento y lenguaje, afectos y emociones en el mundo de las relaciones sociales.

- Dimensión práxica y poiética: Es el reconocimiento de las virtualidades del trabajo cotidiano y del esfuerzo, disciplina, constancia que este implica.

- Dimensión aporética: Alude a las sombras y luces, alegrías y tristezas, realizaciones y problemas que se recrean en la vida cotidiana y que forman parte constitutiva de la condición e historicidad humanas.

- Dimensión lúdico-festiva: Los juegos y las fiestas hacen parte del rito del ser humano, tiñen el fluir de la vida cotidiana representando situaciones propias de la vida corriente que rompen la ceremonia e impiden la rigidez a la vez que flexibilizan los trabajos y responsabilidades de la vida.

- Dimensión teológica: En el hombre, "la articulación entre ciencia y fe es connatural, por el reconocimiento a la armonía y distinción que se da entre esos saberes que no son excluyentes sino complementarios en el gran tema del conocimiento humano" (p.34).

Al igual que Cuéllar (2009), Sierra (2013) han profundizado en los ejes estructurales de la vida cotidiana, los cuales presentan puntos de encuentros con las categorías descritas arriba:

- El mundo familiar y el mundo extraño: Estos mundos son co-constitutivos y cogenerativos. Forman una dicotomía fundamental en el espacio de la cotidianidad. La familiaridad, es un sentimiento de co-pertenencia con el entorno y lo existente. Es un vínculo irreflexivo y afectivo con el mundo de la vida y no una posición consciente de una categoría identitaria.

- Sentirse en casa y lo público: Sentirse en casa expresa el mayor grado de familiaridad e intimidad, la cual excede la esfera pública y trasciende a la esfera privada. "El sentirse casa levanta al mismo tiempo la fuerte muralla de un cotidiano que se reduce a su núcleo duro; ese que permite nuestra maestría de la vida y que excluye otros modos de vivir, decir y hacer" (p.17).

- El tiempo ordinario y el excepcional: "La temporalidad cotidiana trata de situarse a medio camino entre el tiempo vivido, subjetivo y personal, y el tiempo objetivo, físico, impersonal. La cotidianidad conjuga un modo de temporalización en el que la inquietud se transforma en quietud" (p.18). Para Begout (2005) "el tiempo cotidiano y ordinario quiere establecerse a medio camino entre el acontecimiento instantáneo y la repetición perpetua y cristaliza así la historicidad humana" (p.470).

A partir de lo recientemente expuesto se puede destacar que la mirada filosófica en la vida cotidiana, permite un mayor discernimiento de esa vida considerada "ordinaria"; "una mejor atención, comprensión, afirmación y valoración de la vida cotidiana le impedirá al filosofar el encerrarse sobre sí mismo en un diletante juego conceptualista y 'metodicista' que victimiza la historia" (Sierra, 2013, p.20).

\section{Sociologías de la Vida Cotidiana}

La sociología se ha preocupado en estudiar la vida cotidiana, surgiendo inclusive un movimiento llamado "sociologías de la vida cotidiana" entre los que se encuentran Citación del artículo: Millán, K. (2017). Pluridiscursividad de la noción de vida cotidiana en las ciencias sociales. Revista Katharsis, N 23, enero-julio 2017, pp.202-217, Disponible en http://revistas.iue.edu.co/index.php/katharsis 
pensadores como Garfinkel, Goffman, Berger \& Luckmann (Cuéllar, 2009). Lo que tienen en común, es que consideran lo social en el plano intersubjetivo, y la cotidianidad como objeto investigable sociológicamente en el orden de la inter o intrasubjetividad (Canales Cerón, 1995).

Durante los años setenta y ochenta aumentó el interés en la sociología por el estudio de la vida cotidiana, desde varias dimensiones: la sociología existencial, dentro de una visión más teórica, la sociología de las emociones, más sustantiva, y el análisis conversacional, más metodológico; la introducción de tema de la vida cotidiana en corrientes neomarxistas, Lefebvre, Heller (Miguélez \& Torns, 1998).

Miguélez \& Torns (1998) aclaran que la sociología de la vida cotidiana "no está caracterizada precisamente por ser una teoría unificada, sino más bien como una teoría paraguas u omnibus de reenganche de diversas procedencias: hay muchas disciplinas que se reclaman de la sociología de la vida cotidiana" (p. 19).

Miguélez \& Torns (1998) conceptualizan las grandes perspectivas con las que se ha caracterizado las sociologías de la vida cotidiana. Una perspectiva la considera como la esfera de la privacidad, equiparándola al dominio de la individualidad o al de las estrategias de resolución de la problemática y de la intendencia de cada día; otra perspectiva convierte a la vida cotidiana en la parte irrelevante y residual de todo lo que es social, equiparando lo social sólo a lo que es institucional, organizacional, estructural o global y, extensivamente, a lo histórico e «importante»; esta idea ha tenido dominio en las teorías macrosociológicas. Otra perspectiva, "aborda la vida cotidiana como el referente real y como germen primario de toda la vida social, como si toda la realidad social fuera una prolongación o extensión conceptual de la vida cotidiana" (p. 21); otras perspectivas consideran la vida cotidiana como una especie de núcleo irreductible e impenetrable a lo social, a manera de entidad autoconsciente, inerte e invariante con relación a la dinámica de las realidades sociales más globales, tal como se deja entender de las perspectivas de Maffesoli, Catani, Certeau.

Para Miguélez \& Torns (1998), actualmente, han emergido teorías sociológicas más integradoras con pensadores como Alexander, Collins, Knorr-Cetina, Cicourel, Bourdieu, Giddens, Touraine, Heller, Lefebvre, que incorporan una visión de un actor que entiende, comprende y actúa sobre las estructuras sociales y construcciones simbólicas, producidas o reproducidas en las situaciones cotidianas a partir de la interacción entre actores, producto y resultado de la interacción y de las determinaciones del contexto estructural.

La vida cotidiana está impregnada de rutinas, símbolos que sugieren procesos de intersubjetividad que cimienta la construcción de saberes en la práctica social (Villegas \& González, 2011; Urreiztieta 2004). La vida cotidiana construye la historia (Adame, 2005), y aunque puede resultar homogénea para todos los sujetos, si se mira de cerca, en cada una de las acciones el ser humano coloca una huella individual, idiosincrásica, sobre el objeto producido por su accionar (De Certeau, 1999), se plantea así, en términos sociales, como la esfera de la autorrealización individual, "producto de la interrelación de tres grandes dimensiones: la individual, la social y la universal, en otras palabras, es el resultado de las relaciones que establecemos con nosotros mismos, con los demás y con el entorno" (Amar, Angarita \& Cabrera, 2003, p.148).

El abordaje de la sociología de la vida cotidiana involucra las categorías de cotidianidad y cotidiano. Lalive (2008) amplia el marco referencial para distinguir un concepto de otro; la diferenciación entre lo cotidiano y no cotidiano, depende del simbolismo Citación del artículo: Millán, K. (2017). Pluridiscursividad de la noción de vida cotidiana en las ciencias sociales. Revista Katharsis, N 23, enero-julio 2017, pp.202-217, Disponible en http://revistas.iue.edu.co/index.php/katharsis 
asociado a las prácticas y a las situaciones; siendo lo cotidiano el conjunto de prácticas casi totalmente descargadas de simbolización.

Lindón (2004), parafraseando a Lefebvre (1972), refiere que lo cotidiano no son prácticas repetitivas carentes de sentido, "lo cotidiano son los actos diarios, pero sobre todo el hecho de que se encadenan formando un todo (...), lo cotidiano no se reduce a la suma o el agregado de acciones aisladas, como el comer, el beber, el vestirse" (p.44). Lindón advierte, que es importante conocer el contexto de los actos que se hacen diariamente y las relaciones que emergen, en tanto estas acciones se efectúan en un espacio y en un tiempo social.

Para Canales Cerón (1995), "lo cotidiano es un campo de eventos que son conocidos, y más precisamente, "convividos" como tales por los sujetos" (p.1). La aproximación más directa a lo cotidiano es a través de la rutina; entendida ésta como más allá de las situaciones y acciones reiterativas, "lo "rutinario", sólo equivale a lo cotidiano en la medida que indique algo más que la "repetición". Debe estar provisto de una particular modalidad de la vivencia" (Canales Cerón, 1995, p.2).

Ahora bien, si lo rutinario equivale a lo cotidiano, la producción y reproducción de rutina -rituales, etiquetas, etc. - conduce al establecimiento de una cotidianeidad (Lalive, 2008). La obviedad también se constituye en una categoría central de lo cotidiano, en cuanto es vivido o "significado desde un particular modo de observación del sujeto. Es una vivencia en que la subjetividad se inscribe en el orden del obvio" (Canales Cerón, 1995, p.3).

La cotidianidad, por su parte, dispone de la necesidad, la experiencia, el conocimiento y la visión de futuro como "procesos históricos, sociales y culturales que llevan a los individuos a construir su propia realidad individual y colectiva, determina los discursos, donde la subjetividad se pliega completamente a la ideología, y responde a lo que escucha como deberes y posibilidades" (Uribe, 2014, p.106).

Hablar de sociología de la vida cotidiana, implica centrarse en la obra de Ágnes Heller (1991). En contrapeso a la sociología fenomenológica de Schütz, ésta pensadora húngara acentúa las cuestiones históricas y materiales de la vida cotidiana, pero al igual que Schütz, Heller (1991) coincide en percibir "la vida cotidiana como un proceso de formación del mundo propio de los actores sociales, dentro del marco más amplio que es la sociedad" (Estrada, 2000, p.21). La construcción de teoría a la vida cotidiana que realiza Heller, "está influenciada primordialmente por Marx, Lukács. Del primero toma como criterio la división social del trabajo, la historia del hombre, el problema de la alienación y la libertad. De Lukács, la conciencia de clase" (Hermoso, 2014, p.320).

La vida cotidiana se traduce para Heller, en una "simple y rutinaria lucha por la supervivencia" (Méndez, 2005, p.54). "La vida cotidiana como referente teórico permite abordar todo tipo de actividades desde las cuales cada sujeto constituye procesos significativos de reproducción social, apropiación cultural y prácticas sociales" (Orellana, 2009, párr. 10).

En la construcción de un concepto objetivo acerca de la vida cotidiana, Heller (1991), enuncia que "el hombre se objetiva en numerosas formas, el hombre, formando su mundo (su ambiente inmediato), se forma también a sí mismo" (p.46). Uribe (2014), retoma la definición propuesta por Heller (1991) y resalta que "la vida cotidiana es la vida de todo hombre. La vive cada cual, sin excepción alguna, cualquiera que sea el lugar que le asigne la división del trabajo intelectual y físico" (p.102). "En el estudio de la vida cotidiana el Citación del artículo: Millán, K. (2017). Pluridiscursividad de la noción de vida cotidiana en las ciencias sociales. Revista Katharsis, N 23, enero-julio 2017, pp.202-217, Disponible en http://revistas.iue.edu.co/index.php/katharsis 
contexto ocupa un lugar preponderante, "la vida cotidiana no está 'fuera' de la historia, sino en el 'centro' del acaecer histórico: es la verdadera 'esencia' de la sustancia social (Heller, 1985: 42)" (Becher, 2014, p.33). Esto refiere un sujeto con un devenir histórico, en un espacio - tiempo condicionado por factores externos e internos que ilustran la vida cotidiana como un espacio de mediación entre procesos micro y macro (Castro, 2002; Lechner, 1990).

La importancia del contexto en el análisis de la vida cotidiana "ha favorecido su estudio en situaciones socio-históricas que han conmocionado fuertemente la vida de la población en general, se trata de variables macro (la guerra, los golpes de Estado, las nuevas tecnologías) que impactan a nivel micro" (Becher, 2014, p.33).

Desde Heller, la vida cotidiana puede presentar dos dimensiones: la particularidad y la especificidad; además de formar parte de la vida de todo hombre cualquiera sea el lugar que ocupe en la división social del trabajo (Becher, 2014). Es decir, la cotidianidad comprende aquellas actividades que el sujeto realiza en tanto individuo y miembro de la sociedad, porque como lo dirá Heller (1994), “en toda sociedad hay, pues, una vida cotidiana: sin ella no hay sociedad" (p.9).

Algunas consideraciones sobre la vida cotidiana en la obra de Heller, las puntualiza Hermoso (2014): lo cotidiano y vida cotidiana lo usa como igual en su obra, la vida cotidiana es heterogénea y sus esferas consolidan una unidad, la vida cotidiana ocupa principalmente: los sentidos, la habilidad física, el espíritu de observación, la memoria, la sagacidad, la capacidad de reaccionar, los efectos; la vida privada está en correlación con la pública se fragmentan por un fenómeno de alienación.

El sociólogo marxista Henri Lefebvre, es otro de los pensadores contemporáneos que se ha ocupado de la vida Cotidiana, su teorización del espacio y los posteriores escritos sobre el Estado, se entrelazan en una relación indisoluble con la vida cotidiana. Goonewardena (2011) a partir de la lectura de Lefebvre, advierte:

(...), está profundamente relacionada con todas las actividades, las engloba con todas sus diferencias y sus conflictos; es su punto de encuentro, su vínculo, su terreno común. Y es en la vida cotidiana donde toma forma y se configura la suma total de las relaciones que hacen de lo humano - y a cada ser humano - un todo. En ella se expresan y realizan esas relaciones que ponen en juego la totalidad de lo real, aunque de cierta manera que es siempre parcial e incompleta: amistad, camaradería, amor, la necesidad de comunicarse, el juego, etc. (p. 97).

La vida cotidiana es el escenario donde se hace posible la espacialidad humana cuyos componentes son: el espacio, el tiempo, las pluralidades de sentido, lo simbólico y las prácticas (Lindón, 2004); su propuesta teórica se opone a la simple recopilación interminable de hechos. "No hay hechos sociales o humanos que no tengan un lazo de unión. Entonces la cotidianidad puede tomarse como ese lazo que une, o bien como el "hilo conductor para conocer la sociedad" (p.44).

Para Rossana Reguillo (2000), "la vida cotidiana se constituye en un lugar estratégico para pensar la sociedad en su compleja pluralidad de símbolos y de interacciones" (p.121), en donde confluyen las estructuras y prácticas de los individuos para la reproducción social, la creatividad y la innovación (Uribe, 2014).

Citación del artículo: Millán, K. (2017). Pluridiscursividad de la noción de vida cotidiana en las ciencias sociales. Revista Katharsis, N 23, enero-julio 2017, pp.202-217, Disponible en http://revistas.iue.edu.co/index.php/katharsis 
El sociólogo Suizo y profesor reconocido de la universidad de Geneva, Christian Lalive, expone que las actividades dadas en la vida cotidiana tienen una forma específica de contarse o relatarse, esto se hace fundamental porque da cuenta de un orden existente en la vida cotidiana de los sujetos, así mismo, muestra como el ser humano define su propia vida cotidiana. Lalive (2008) propone frente a este concepto:

- La vida cotidiana tiene un carácter de evidencia para el sentido común. Es decir, permite ratificar o resignificar lo que sucedió sea desde el relato, el escrito u otras evidencias que confirman los sucesos.

- El autor manifiesta que todo relato tiene diversos puntos de anclaje, es decir, existe siempre un acto con el cual se inicia para detallar en lo que consistió nuestra vida cotidiana, esto se hace importante pues da cuenta de que la rutina es un aspecto que determina la manera como concebimos y nombramos nuestros actos cotidianos.

- Los sujetos conciben su vida cotidiana como los actos que desarrollan de manera automática, es decir, estos actos que carecen de una conciencia al realizarlos que se convierten, como los llama el autor, en rituales.

La sociología de la vida cotidiana reconoce que el ser humanos se construye a partir de la interacción social, en un proceso relacional donde la sociedad le determina ciertos comportamientos y rituales, así mismo, en un sentido de singularidad, aporta a su construcción un componente de individualidad, nutriendo con sus propias percepciones el mundo que le rodea.

Así como las sociedades se transforman continuamente, la vida cotidiana de los sujetos también evoluciona, éstos van adquiriendo nuevos hábitos y estilos de vida, que hacen de la vida cotidiana un fenómeno de historicidad y cambio.

\section{La mirada Antropológica de la vida cotidiana}

La arqueología es una disciplina que desde la antropología se ha interesado teóricamente por la vida cotidiana como herramienta de análisis en los trabajos de excavación y en la explicación de patrones de asentamiento y urbanización. Si bien la etnología y la antropología social se han valido de descripciones de la cotidianidad, éstas disciplinas no han centrado su interés teórico en problematizar la vida cotidiana como vía de acceso epistemológico a la realidad social (Zamora, 2005).

Durán \& Gutiérrez (2005) resaltan que la antropología le ha otorgado un importante reconocimiento al concepto de vida cotidiana, en tanto ahí se tejen los interrogantes sobre las personas, su mundo social y los fenómenos emergentes en el acontecer del mundo. Juan (2008) advierte frente al concepto, una mirada dialéctica, considerando que los hechos sociales son a la vez históricos. A esta noción de historicidad de la vida cotidiana se le suma la noción de conflicto, que son básicas en las investigaciones antropológicas (Zamora, 2015). En este sentido, la vida cotidiana está integrada por los saberes de la realidad, los ritos y los procesos perceptuales de apropiación cultural que ahí se desarrollan (Massó, 2012). Para Montesinos (1996), la vida cotidiana es "el conjunto de valores, orientaciones, actitudes, expectativas (...) normas, conductas y prácticas sociales” (p. 191), las cuales se expresan en un espacio social; las interacciones emergentes en dicho espacio intervienen en las emociones

Citación del artículo: Millán, K. (2017). Pluridiscursividad de la noción de vida cotidiana en las ciencias sociales. Revista Katharsis, N 23, enero-julio 2017, pp.202-217, Disponible en http://revistas.iue.edu.co/index.php/katharsis 
de los sujetos y las formas como son interpretadas en la realidad y en los espacios cotidianos (Mora, 2005; Durán, 2005).

la concepción de antropología fundada en la vida cotidiana otorga la posibilidad de integrar el quehacer con la vivencia al llevarse a cabo desde la vivencia. Las vivencias no son excluyentemente personales, sino sociales. Por tanto, requieren ser consideradas en el ejercicio cognoscitivo, ya que es el principal instrumento por el cual podemos conocer (Durán \& Gutiérrez, 2005, p.119).

Si bien no se evidencia una construcción propia de la categoría de cotidianidad desde la antropología, se retoman elementos de la filosofía, especialmente de la propuesta de Giannini (1999), que presenta algunas ventajas en las investigaciones antropológicas: representa un abanico muy amplio de posibilidades de estudio, permite tener presente la importancia de las reglas en la constitución de un grupo social, facilita la comprensión y explicación de las acciones aparentemente paradójicas, facilita enlazar los aspectos micro y macro, prevé el entendimiento de los procesos de cambio y de transformación y tiene en cuenta las relaciones de poder que hay al interior de la comunidad (Zamora, 2005).

\section{Conclusiones}

Las ciencias sociales se han interesado por la vida cotidiana específicamente en las estructuras del mundo de la vida y de las acciones que se derivan de dicho mundo: los actos rutinarios, la cultura, los ritos, el juego, las festividades, la muerte, lo particular y efímero de la realidad social, trasciende de la mirada pasiva y de la obviedad del espectador, para asumir una crítica reflexiva propicia de análisis.

Pese al abordaje de las distintas tradiciones aquí expuestas, no hay un consenso en la definición de la vida cotidiana ni en las categorías que la integran, como es el caso de la cotidianidad. Este carácter pluralista va a variar dependiendo la disciplina, los autores y los fines con que sea abordado. Es de resaltar que la vida cotidiana trasciende el conocimiento, en tanto integra significados y sentidos de las acciones humanas, derivando en una referencia experiencial.

Algunos elementos trasversales sobre la vida cotidiana en la filosofía, la sociología y la antropología es el carácter dicotómico del concepto (cotidiano v/s no cotidiano, lo público v/s lo privado etc.,), la generalidad de espacio-tiempo en la que se enmarca, su representación socio-histórica, la interrelación de lo micro/macro en el contexto individual y social y los cambios y nuevos estilos de vida que tienen lugar en la cotidianidad.

En estos tiempos postmodernos, es esencial que la reivindicación de la vida cotidiana sea creativa, critica y reflexiva, para no convertirla en quimera (Sierra, 2013). Se hace importante retomar los interrogantes de cómo se está viviendo, cuáles han sido las implicaciones de la globalización y el capitalismo en la intersubjetividad del ser humano, el impacto en los proyectos y políticas de vida del individuo. Y, por último, pero no menos importante, tener presente que la manera como el ser humano logra dar cuenta de su

Citación del artículo: Millán, K. (2017). Pluridiscursividad de la noción de vida cotidiana en las ciencias sociales. Revista Katharsis, N 23, enero-julio 2017, pp.202-217, Disponible en http://revistas.iue.edu.co/index.php/katharsis 
existencia y de su ejecución en el mundo, es por medio del relato de su vida cotidiana y está tendrá impacto en las sociedades venideras.

\section{Referencias}

Acevedo, M. (2011). Aportes de la teoría social de Alfred Schutz para pensar la política y la acción colectiva. Trabajo y Sociedad. 15(17), 83-94. Recuperado de http://www.scielo.org.ar/scielo.php?script=sci_arttext\&pid=S1514$68712011000200007 \& \operatorname{lng}=$ es\&nrm=iso

Acosta, J. (2013). Filosofía y pensamiento crítico. Sincronía, (63), 18-20. Recuperado de http://sincronia.cucsh.udg.mx/pdf/2013_a/ortiz_64_2013.pdf

Adame, M. (2005). Hacia una socioantropología de la vida cotidiana y su crítica. Tiempo, 65-71. Recuperado de http://www.uam.mx/difusion/revista/mayo2005/adame.pdf

Amar, J., Angarita, C., Cabrera, K. (2003). Construcción de imaginarios infantiles y vida cotidiana. Psicología desde el Caribe, (12), 134-172. Recuperado de http://www.redalyc.org/pdf/213/21301209.pdf

Arellano, A., Chávez M., Anguiano, V. (2012). Vida cotidiana, problemáticas sociales y expectativas de vida en estudiantes de la Facultad de Letras y Comunicación de la Universidad de Colima, México. Exploración del significado social mediante Redes Semánticas Naturales (RSN). Estudios sobre las Culturas Contemporáneas. 18(35), 139-173. Recuperado de http://www.redalyc.org/articulo.oa?id=31623308007

Arendt, H. (2013). The human condition. University of Chicago Press.

Becher, Y. (2014). El tiempo y el espacio en la cotidianidad ¿cómo inciden en los vínculos interpersonales? Questión. Revista especializada en periodismo y comunicación. 1(43), 32-39. Recuperado de http://perio.unlp.edu.ar/ojs/index.php/question/article/view/2194/1964

Begout, B. (2005). La Découverte du quotidiene. Paris: Allia.

Begout, B. (2009). La potencia discreta de lo cotidiano. Persona y Sociedad. 23 (1), 9-20. Recuperado https://www.academia.edu/1784423/_2009_Bruce_B\%C3\%A9gout._La_potencia_ discreta_de_lo_cotidiano_Trad._P._Mena_E._Mu\%C3\%B1oz_?auto=download

Camarena Adame, M., Tunal Santiago, G. (2008). El estudio de la vida cotidiana como expresión de la cultura. Revista del Centro de Investigación. Universidad La Salle, 8(29), 95-107. Recuperado de http://www.redalyc.org/articulo.oa?id=34282910

Canales Cerón, M. (1995). Sociologías de la vida cotidiana, En: M. Garretón, y O. Bravo (Comps). Dimensiones actuales de la sociología. Madrid: Allende Editores.

Castoriadis, C. (1993). La institución imaginaria de la sociedad. Vols. 1 y 2. Tusquest: Buenos Aires.

Castro, J. (1996). Vida cotidiana y profesión. Educación física y deporte. 18(2), 91-99. Recuperado de http://aprendeenlinea.udea.edu.co/revistas/index.php/educacionfisicaydeporte/articl e/view/4567/4011

Citación del artículo: Millán, K. (2017). Pluridiscursividad de la noción de vida cotidiana en las ciencias sociales. Revista Katharsis, N 23, enero-julio 2017, pp.202-217, Disponible en http://revistas.iue.edu.co/index.php/katharsis 
Castro, G. (2002). Los actores y los escenarios de encuentro en la sociedad actual. KAIROS Revista de Temas Sociales, $N$ 11, Recuperado de http://www2.fices.unsl.edu.ar/ kairos/k11-04.htm

Castro, G. (2004). Los jóvenes: entre los consumos culturales y la vida cotidiana. KAIRÓS, Revista de Temas sociales. (14), 1-14. Recuperado de http://www.revistakairos.org/k14-archivos/Graciela\%20Castro.pdf

Collado, M. (2002). En torno a la historia de la vida cotidiana. Revista de la Universidad de México, (615), 5-7. Recuperado de http://www.revistadelauniversidad.unam.mx/ojs_rum/files/journals/1/articles/15429 /public/15429-20827-1-PB.pdf

Cuéllar, H. (2009). Hacia un nuevo humanismo: filosofía de la vida cotidiana. En-claves del Pensamiento. 3(5), 11-34. $\quad$ Recuperado de http://www.scielo.org.mx/scielo.php?script=sci_arttext\&pid=S1870879X2009000100001

De Certeau, M. (1999). La invención de lo cotidiano. Artes de hacer. Vol. 1. México: Universidad Iberoamericana

Díaz, M. (2010). La vida cotidiana en la época moderna: disciplinas y rechazos. Historia Social, (66), 41-56. Recuperado de http://www.jstor.org/stable/40658072

Durán, T. (2005). Duplicando la antropología en la Araucanía de Chile. Revista anthropos: Huellas del conocimiento, (207), 23-42. Recuperado de https://dialnet.unirioja.es/ejemplar/112079

Durán, T., Gutierrez, L. (2005). El quehacer de la Antropología en la vida cotidiana. Líder: revista labor interdisciplinaria de desarrollo regional, (14), 105-120. Recuperado de https://dialnet.unirioja.es/servlet/articulo?codigo $=2054208$

Estrada, M. (2000). La vida y el mundo: distinción conceptual entre mundo de vida y vida cotidiana. Sociológica. (43), 103-151. Recuperado de http://www.revistasociologica.com.mx/pdf/4306.pdf

Grathoff, R. (1989) Milieu und Lebenswelt. Eine Einführung in die phänomenologischeSoziologie und die sozialphänomenologische Forschung. Frankfurt am Main: Suhrkamp Verlag.

Giannini, H. (1999). La "reflexión" cotidiana. Hacia una arqueología de la experiencia. Santiago de Chile: Editorial Universitaria.

Goonewardena, K. (2011). Henri Lefebvre y la revolución de la vida cotidiana, la ciudad y el Estado. Urban, (2), 25-39. Recuperado de http://www2.aq.upm.es/Departamentos/Urbanismo/institucional/articulos-ns/ns02septiembre-2011/henri-lefebvre-y-la-revolucion-de-la-vida-cotidiana-la-ciudad-yel-estado/

Heller, A. (1991). Sociología de la vida cotidiana. Barcelona: Ediciones Península.

Heller, A. (1994). La revolución de la vida cotidiana. Barcelona: Ediciones Península.

Hermoso, V. (2014). La sociología de la vida cotidiana en Agnes Heller. ARJÉ Revista de Postgrado FACE-UC. 8(14), 305-321. Recuperado de http://servicio.bc.uc.edu.ve/educacion/arje/arj14esp/art14.pdf

Hernández, Y., Galindo, R. (2007). El concepto de intersubjetividad en Alfred Schutz.Espacios Públicos. $10 \quad$ (20), 228-240. Recuperado de http://www.redalyc.org/pdf/676/67602012.pdf

Citación del artículo: Millán, K. (2017). Pluridiscursividad de la noción de vida cotidiana en las ciencias sociales. Revista Katharsis, N 23, enero-julio 2017, pp.202-217, Disponible en http://revistas.iue.edu.co/index.php/katharsis 
Juan, S. (2008). Un Enfoque Socio-Antropológico Sobre la Vida Cotidiana: Automatismos. Espacio abierto, 17(3), 431-454. Recuperado de http://www.redalyc.org/articulo.oa?id=12217304

Lalive, C. (2008). La vida cotidiana: Construcción de un concepto sociológico y antropológico. Sociedad Hoy. (14) 9-31. Recuperado de http://www.redalyc.org/articulo.oa?id=90215158002

Lechner, N. (1990). Los patios interiores de la democracia. Subjetividad y política. Chile: Fondo de Cultura Económica.

Lindón, A. (2004). Las huellas de Lefebvre sobre la vida cotidiana. Veredas, Revista del pensamiento sociológico, $8, \quad 39-60 . \quad$ Recuperado de http://www.lefthandrotation.com/museodesplazados/download/Lindon\%20\%20Las\%20huellas\%20de\%20Lefebvre\%20sobre\%20la\%20vida\%20cotidiana.pdf

Perera, M. (Julio de 1997). Crisis, reajuste y Vida Cotidiana. En: XXVI Congreso Interamericano de Psicología. Sao Paulo. Brasil.

Massó, P. (2012). Hacia un enfoque antropológico en los estudios de recepción mediática. Razón y palabra, (79), Recuperado de http://razonypalabra.org.mx/N/N79/V79/60_Masso_V79.pdf

Méndez, L. (2005). Modernidad tardía y vida cotidiana. Sociológica. 20(58), 53-75. Recuperado dehttp://www.redalyc.org/pdf/3050/305024759003.pdf

Miguélez, F., Torns, T. (1998). Introducción al análisis del trabajo y de la vida cotidiana. Papers: revista de sociología, (55), 9-25. Recuperado de http://www.raco.cat/index.php/papers/article/viewFile/25502/25335

Montero, I. y León, O. (2007). A guide for naming research studies in Psychology. International Journal of Clinical and Health Psychology, 7, 847-862. Recuperado de http://www.aepc.es/ijchp/GNEIP07_es.pdf

Montesinos, R. (1996). Vida cotidiana, familia y masculinidad. Revista Sociológica, 11(31), 183-203. Recuperado de http://www.revistasociologica.com.mx/pdf/3110.pdf

Mora, M. (2005). Emoción, género y vida cotidiana: apuntes para una intersección antropológica de la paternidad. Espiral, 12 (34), 9-35. Recuperado de http://www.redalyc.org/articulo.oa?id=13803401

Morales, N. (2001). Filosofía de lo cotidiano y el ritmanálisis. Fermentum, 11(32), 515-24. Recuperado de http://www.redalyc.org/articulo.oa?id=70511233012

Orellana, D. (2009). La Vida Cotidiana. Revista Universitaria de Investigación y Diálogo Académico, CONHISREMI, 5(2). Recuperado de http://conhisremi.iuttol.edu.ve/pdf/ARTI000066.pdf

Perera, M. (2012). Enfoque Teórico Metodológico para el Estudio de la Vida Cotidiana. Global Journal of Community Psychology Practice, 3(4). Recuperado de http://www.gjcpp.org/pdfs/2012-Lisboa-053.pdf

Reguillo, R. (2000). La clandestina centralidad de la vida cotidiana. Valencia (Venezuela), Universidad de Carabobo.

Romero, M. (2001). Vocación de la filosofía. Revista Xipe Totek, 10 (1). Recuperado de http://webcache.googleusercontent.com/search?q=cache:http://www.xipetotek.iteso $. \mathrm{mx} /$

Santos Herceg, J. (2014). Cotidianidad: trazos para una conceptualización filosófica. Alpha (Osorno), (38), 173-196. Recuperado de

Citación del artículo: Millán, K. (2017). Pluridiscursividad de la noción de vida cotidiana en las ciencias sociales. Revista Katharsis, N 23, enero-julio 2017, pp.202-217, Disponible en http://revistas.iue.edu.co/index.php/katharsis 
http://www.scielo.cl/scielo.php?script=sci_arttext\&pid=S071822012014000100012

Sierra, G. (2013). Vida cotidiana y filosofía. Pertenencia y distancia. Revista de Filosofía, 135, 9-42. Recuperado de http://revistas.ibero.mx/filosofia/articulo_detalle.php?id_volumen=6\&id_articulo=1 27

Uribe Fernández, M. (2014). La Vida Cotidiana como espacio de construcción social. Procesos Históricos. (25), 100-113. Recuperado de http://www.redalyc.org/pdf/200/20030149005.pdf

Urreiztieta, M. (2004). La sociología interpretativa: globalización y vida cotidiana. Espacio Abierto. $13(3), \quad 457-\quad 470 . \quad$ Recuperado de http://www.redalyc.org/articulo.oa?id=12213306

Villegas, M., González, F. (2011). La investigación cualitativa de la vida cotidiana: medio para la construcción de conocimiento sobre lo social a partir de lo individual. Psicoperspectivas, 10(2), 35-59. Recuperado de http://www.scielo.cl/pdf/psicop/v10n2/art03.pdf

Zamora, I. (2005). La importancia de la vida cotidiana en los estudios antropológicos. Líder: revista labor interdisciplinaria de desarrollo regional, (14), 123-143. Recuperado de https://dialnet.unirioja.es/servlet/articulo?codigo=2054217

Citación del artículo: Millán, K. (2017). Pluridiscursividad de la noción de vida cotidiana en las ciencias sociales. Revista Katharsis, N 23, enero-julio 2017, pp.202-217, Disponible en http://revistas.iue.edu.co/index.php/katharsis 